\title{
Demystifying the Meaning of Active Learning in Postsecondary Biology Education
}

Emily P. Driessen, ${ }^{* *}$ Jennifer K. Knight, ${ }^{\ddagger}$ Michelle K. Smith,$\$$ and Cissy J. Ballen ${ }^{\dagger}$

${ }^{\dagger}$ Department of Biological Sciences, Auburn University, Auburn, AL 36849; 'Department of

Molecular Cellular and Developmental Biology, University of Colorado, Boulder, CO 80309;

§Department of Ecology and Evolutionary Biology, Cornell University, Ithaca, NY 14853

\begin{abstract}
Active learning is frequently used to describe teaching practices, but the term is not well-defined in the context of undergraduate biology education. To clarify this term, we explored how active learning is defined in the biology education literature ( $n=148$ articles) and community by surveying a national sample of biology education researchers and instructors ( $n=105$ individuals). Our objectives were to increase transparency and reproducibility of teaching practices and research findings in biology education. Findings showed the majority of the literature concerning active learning never defined the term, but the authors often provided examples of specific active-learning strategies. We categorized the available active-learning definitions and strategies obtained from the articles and survey responses to highlight central themes. Based on data from the BER literature and community, we provide a working definition of active learning and an Active-Learning Strategy Guide that defines 300+ active-learning strategies. These tools can help the community define, elaborate, and provide specificity when using the term active learning to characterize teaching practices.
\end{abstract}

\section{INTRODUCTION}

The promotion of undergraduate biology knowledge in the United States has immediate and long-term implications for increasing national science literacy, providing high-quality education to the science, technology, engineering, and mathematics (STEM) workforce, and contributing to critical scientific advances. To meet these objectives, calls to action formalized priorities and made specific recommendations aimed at improving undergraduate biology education nationwide. For example, after extensive discussions among biology faculty, students, and administrators, the American Association for the Advancement of Science (2009) published a formative document, Vision and Change: A Call to Action, which advocated for "student-centered classrooms" and outlined six core competencies intended to guide undergraduate biology education: 1) apply the process of science; 2) use quantitative reasoning; 3) use modeling and simulation; 4) tap into the interdisciplinary nature of science; 5) communicate and collaborate with other disciplines; and 6) understand the relationship between science and society. Another call to action came from the President's Council of Advisors on Science and Technology (2012), who proposed five recommendations to change undergraduate STEM education, including the adoption of "evidence-based teaching practices."

Although these pushes for "student-centered" and "evidence-based" practices are relatively recent, they stem from ideologies that are more than a century old. Specifically, Dewey (1916) wrote, "Learning means something which the individual does when he studies. It is an active, personally conducted affair" (p. 390). Based upon this work, Pesavento et al. (2015) identified Dewey as one of the earliest and most influential advocates of what we now know as active learning. Subsequently, others
Brian Sato, Monitoring Editor

Submitted Apr 14, 2020; Revised Jun 16, 2020; Accepted Jul 30, 2020

CBE Life Sci Educ December 1, 2020 19:ar52

DOI:10.1187/cbe.20-04-0068

*Address correspondence to: Emily P. Driessen (epd0016@auburn.edu).

(c) 2020 E. P. Driessen et al. CBE-Life Sciences Education $\odot 2020$ The American Society for Cell Biology. This article is distributed by The American Society for Cell Biology under license from the author(s). It is available to the public under an Attribution-Noncommercial-Share Alike 3.0 Unported Creative Commons License (http://creativecommons.org/licenses/ by-nc-sa/3.0)

"ASCB®" and "The American Society for Cell Biology $\circledR^{\prime \prime}$ are registered trademarks of The American Society for Cell Biology. 
expanded on and institutionalized terms such as "student-centered" and "evidence-based" practices (Piaget, 1932; Montessori, 1946; Vygotsky, 1987; Papert, 1980; Brown et al., 1989; Turkle and Papert, 1990; Ackermann, 2001, Cook et al., 2012). While this body of work is critical to our understanding of active learning, the ways in which practitioners and researchers currently use the term are often vague.

Despite this ambiguity, research concerning the effectiveness of active learning in the classroom has continued. For example, a landmark meta-analysis compared student achievement and failure rates between undergraduate science, engineering, and mathematics classes that used active-learning approaches and those that used lecture (Freeman et al., 2014). Findings demonstrated that active learning decreased failure rates by $55 \%$ and increased student examination performance by approximately half a standard deviation. To define active learning for the purposes of clarity and transparency in their research, Freeman et al. (2014) developed a definition based on responses from 338 biology departmental seminar audience members: "Active learning engages students in the process of learning through activities and/or discussion in class, as opposed to passively listening to an expert. It emphasizes higher-order thinking and often involves group work" (pp. 8413-8414). This definition guided their inclusion criteria for the study, and it is one of the few examples of clearly defined parameters.

Although many articles do not define the exact parameters of active learning, the research has demonstrated the positive effects of active learning on student achievement and affect across multiple contexts. For example, researchers demonstrated that active learning yields disproportionate learning gains among the most at-risk student groups, such as first-generation college attendees and those who identify with races/ethnicities historically underrepresented in STEM fields (Beichner et al., 2007; Haak et al., 2011; Eddy and Hogan, 2014; Ballen et al., 2017; Wilton et al., 2019; Bauer et al., 2020). Additionally, a meta-analysis conducted by Theobald et al. (2020) demonstrated that active learning narrows achievement gaps for underrepresented students in undergraduate STEM disciplines. However, it is important to note that the definitions of active learning used in these articles vary from the antithesis of lecture (Theobald et al., 2020) to listing the specific strategies that characterize the term (e.g., in-class activities, prelecture preparation, and frequent low-risk assessment; Ballen et al, 2017).

Despite the varying parameters of the term, postsecondary institutions have increasingly embraced the use of the term "active learning" (Pfund et al., 2009; Aragón et al., 2018). Examples include institution-wide initiatives (e.g., the Science Education Initiatives at University of Colorado and University of British Colombia, and the Active Learning Initiative at Cornell University), the Summer Institutes on Scientific Teaching (www.summerinstitutes.org), and the Obama Administration's Active Learning Day (https://obamawhitehouse.archives.gov/ blog/2016/10/25/active-learning-day-america). Additionally, more than three-fourths of colleges and universities in the United States provide some type of active-learning classrooms, defined as those that offer flexibility in design to facilitate different types of teaching (Alexander et al., 2019).

Despite these institutional supports and documented positive impacts, the term "active learning" itself is difficult to ascertain from a review of literature. For example, Eddy et al. (2015) explained that active learning is a complex process that encompasses both teaching methods and student learning. Drew and Mackie (2011) noted the meaning of active learning may be dichotomous, as it has been considered a theory of learning as well as a set of pedagogical strategies. Although attempts have been made to define active learning as a theory (Freeman et al., 2014; Connell et al., 2016; Moss-Racusin et al., 2016; Auerbach and Schussler, 2017; Jeno et al., 2017) as well as a set of strategies in biology education research (BER; Tanner, 2013; Miller and Tanner, 2015), these attempts are not always 1) streamlined or easy to follow, 2) regularly used in the literature, 3) supported by literature or data, and/or 4) comprehensive. This outcome is problematic when trying to understand what exactly active learning encompasses.

Notably, the variation in the conceptualization of active learning reflects a state of scientific revolution. According to Kuhn (1970), the development of a science has alternating phases (i.e., normal and revolutionary). Normal science, equated to puzzle-solving, comes with a reasonable chance of solution via familiar methods and can be solved by one person. On the other hand, a revolutionary phase involves a collectively negotiated revision to an existing belief or practice. While discipline-based education researchers address questions about the efficacy of recently developed teaching strategies, those strategies are commonly being binned under active learning, which is an ill-defined term. To improve our field, it is important to negotiate how the community interprets and understands this term.

Furthermore, demystifying active learning in undergraduate biology has direct applications for teaching and research. The broad interpretation of active learning may discourage instructors from trying new instructional practices and may ultimately serve as a barrier to implementation (Kreber and Cranton, 2000; O’Donnell, 2008; Stains and Vickrey, 2017). It may additionally serve as a barrier to experimental replication in discipline-based education research (DBER) communities, because there are no agreed-upon standards or criteria for inclusion or exclusion. Given this, we investigated the following four questions in the context of undergraduate biology courses: 1) How does the BER literature use and define the term "active learning"? 2) How does the BER community define the term "active learning"? 3) How are active-learning strategies described in the BER literature? and 4) How are active-learning strategies described by the BER community? We addressed these research questions through a review of BER literature and a survey of the BER community. We expect that, by developing ways to efficiently communicate active learning in the context of biology education, we will encourage teaching innovations and the adoption of common research-based practices.

\section{METHODS}

\section{Analyzing the Literature}

To address how the BER literature defines and uses the term "active learning," we extracted information from peer-reviewed biology education journals. Many peer-reviewed journals publish BER, including Advances in Physiology Education, American Biology Teacher, Anatomical Science Education, BioScience, Journal of College Science Teaching, CBE-Life Sciences Education (LSE) and the Journal of Microbiology \& Biology Education; 
however, we chose to examine only two of them, acknowledging that this is an exploratory, nonexhaustive study. We chose LSE and the Journal of Microbiology \& Biology Education because of their prominence, history, and readership (see websites: www.lifescied.org; www.asmscience.org/content/journal/jmbe). We searched for the term "active learning" in the titles, abstracts, or text of research articles published in those two journals, and only papers that used this term were included in our analysis. To get a contemporary snapshot of how the term is used, we only included articles published over the 3 years that preceded the start of the study, from January 1, 2016, to December 31, 2018. We collected data within the same time span from CourseSource, an online journal that exclusively publishes evidence-based biology teaching materials for undergraduate classrooms and laboratories (www.coursesource.org/about). We included this journal, because it captures how biology instructors translate findings from the active-learning research literature into classroom practice. All CourseSource lesson articles included an Active Learning section in which authors list and/or explain their instructional approaches, so we included all published papers in the final analysis.

Once we selected articles based upon our search criteria, three of the authors (C.J.B., M.K.S., and J.K.K.) read the articles and extracted the relevant text surrounding the search term "active learning." If active learning was defined in the article, it usually occurred after the term was first mentioned in the introduction or the methods. Articles that described specific active-learning strategies often included them in the methods section of the paper, after introducing active learning broadly as an effective form of instruction. Because this text placement could vary, we searched through each article to make sure we included any definition or strategies that the article's authors described.

To determine how BER articles use and define the term "active learning," we first examined to what extent, if at all, articles included a definition of active learning. Articles that met the inclusion criteria were binned into six categories, first based on whether researchers followed their definition of active learning with a citation (i.e., "literature based") or did not include a citation (i.e., "not literature based"). We then recorded whether articles included specific active-learning strategies, either in addition to a formal definition or in place of a definition. Our final list of categories included articles that provided: 1) a definition of active learning that was literature based (i.e., included a citation) with examples of active-learning strategies; 2) a definition of active learning that was not literature based (i.e., did not include a citation) with examples of active-learning strategies; 3) a definition of active learning that was literature based with no examples of active-learning strategies; 4) a definition of active learning that was not literature based and had no examples of active-learning strategies; 5) no active literature definition with active-learning strategies; and 6) no active literature definition and no active-learning strategies (Figure 1).

\section{Surveying the Community}

In addition to combing the literature, we collected survey data from members of the Society for the Advancement of Biology Education Research (SABER; a scientific community of discipline-based education researchers and teaching practitioners

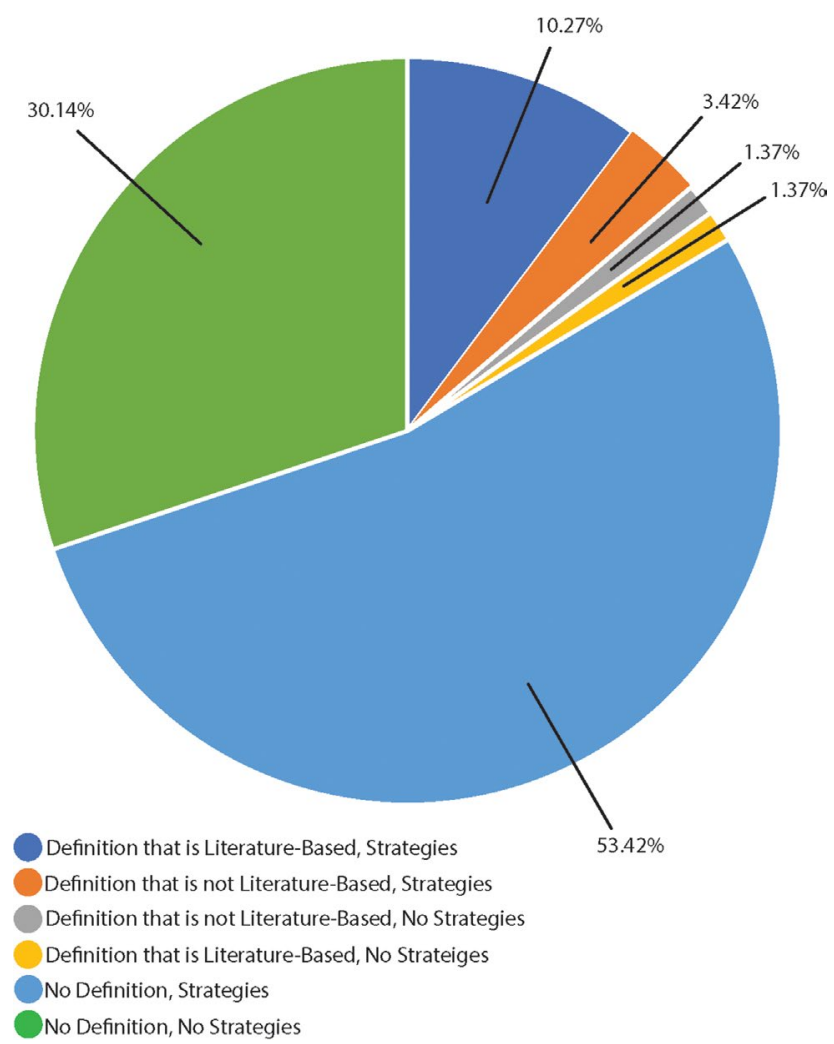

FIGURE 1. Ways in which articles from LSE, the Journal of Microbiology \& Biology Education, and CourseSource use the term "active learning."

who focus on improving postsecondary biology education through evidence and theory) via the Listserv. We selected SABER as a group to survey, because it is the "world's largest organization dedicated to scientifically exploring how to teach biology most effectively" (https://saberbio.wildapricot.org).

Through the survey, we collected demographic information from the survey participants, including institution type, employment position (i.e., faculty, postdoc, graduate student, etc.), level of biology class (e.g., lower level, upper level, etc.), class size, country of instruction, and frequency of active-learning instruction practice (Table 1). Additionally, the survey included the following two prompts: 1) "In your own words, define the term 'active learning' in the context of undergraduate biology classrooms"; and 2) "List the active-learning techniques that you use in biology classrooms." All research was conducted in accordance with the Cornell University Institutional Review Board (Cornell IRB protocol no. 1810008360).

\section{Data Categorization}

After we obtained both active-learning definitions and strategies from the surveys and the literature, we analyzed the data. Specifically, we started by creating two data sets. These were created by 1) taking the active-learning definition text from the literature and from the surveys and combining it into one Excel spreadsheet, and 2) taking the active-learning strategies text from the literature and from the surveys and combining it into another Excel spreadsheet. Both data sets were then categorized. 
TABLE 1. Information about SABER members who participated in the survey

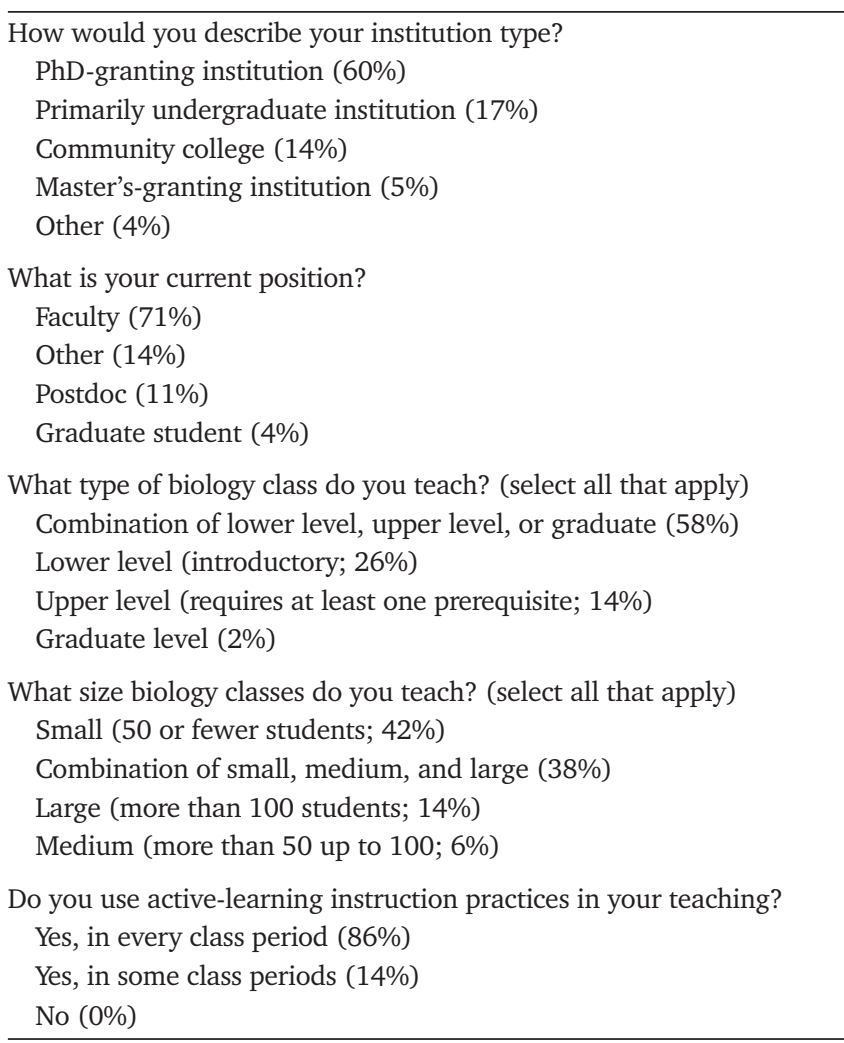

\section{Categorization of Active-Learning Definitions}

After combining the active-learning definitions from both data sources (i.e., the literature and surveys), we analyzed the active-learning definition data. Using open coding (Strauss, 1987; Strauss and Corbin, 1990), a method rooted in the grounded theory framework (Glaser et al., 1968), three of the authors (J.K.K., M.K.S., and C.J.B.) reviewed the responses and identified recurring themes. Using the methodology from Saldaña (2015), the authors compared their notes and developed a final set of 10 categories: students interacting or engaging with the material, not traditional lecture, group work, scaffolding or constructivism, problem solving, individual formative assessments (e.g., through the use of personal response systems), student-centered pedagogy, application or synthesis of material, student ownership of learning, and evidence-based teaching. The authors binned each article's use of the term into as many categories of active learning as appropriate. At first, the three coders placed $71 \%$ of the definitions in the same categories. After discussion, coders resolved all differences and shared 100\% agreement. Then, we calculated how often the definitions appeared in each of the 10 categories for the surveys and the literature individually.

\section{Categorization of Active-Learning Strategies}

After merging the strategies from the literature with those obtained from the surveys, we analyzed the active-learning strategy data. Using open coding, three researchers (E.P.D. and two undergraduate students) developed a set of nine categories
(Supplemental Appendix A): metacognition, discussion, group work, assessment, practicing core competencies, visuals, conceptual class design, paperwork, and games. To improve our collective ability to reliably categorize strategies, we needed definitions of each strategy listed. Because no such list of definitions existed, we defined each of the unique strategies (Supplemental Appendix B) using published literature or dictionary definitions (Supplemental Appendix C). The utility of this list, which we call the Active-Learning Strategy Guide can also be used by the education research community and disciplinary practitioners interested in learning about active-learning strategies. Using the Active-Learning Strategy Guide, we were able to categorize the strategies with an initial percentage of agreement of $75 \%$. After discussion, the researchers resolved any differences with discussion for a final percentage of agreement of $100 \%$.

\section{RESULTS}

How Does the BER Literature Use and Define the Term "Active Learning"?

Of the 148 articles that fit our search criteria, the majority did not provide a definition for the term "active learning," but instead listed examples of specific active-learning strategies (53.42\%; Figure 1). The second most common approach used in the articles provided less information: no definition and no list of relevant strategies (30.14\%). Overall, this demonstrates the overwhelming majority of the active-learning literature (83.56\%) did not define active learning.

To address how the BER literature defines active learning, we focused on articles that provided a definition of the term, with or without the inclusion of one or more references. Among the 24 articles that defined active learning (Table 2), 17 articles (74\%) provided literature citations and seven (26\%) did not. Of the 17 articles that defined active learning using references to the literature, five of them (29\%) cited Freeman et al. (2014). There was a bit of variation in reference use, with a total of 43 different references mentioned (Supplemental Appendix D).

The 17 definitions obtained from the literature were categorized as previously mentioned. The most represented category defined active learning as "students interacting or engaging with the material," followed by the category that emphasizes what active learning is not: "not traditional lecture" (Figure 2A).

\section{How Is the Term "Active Learning" Defined by the BER Community?}

We received responses from 105 individuals from a range of institutions across the United States (Table 1). In general, survey participants' definitions fit into the same categories as those in the published literature surveyed (Figure 2A). The most common definition of active learning, from the BER community, was "interacting/engagement" with the material. The second most common categorized definition was "not lecturing/listening," followed by "group work."

\section{How Are Active-Learning Strategies Described in the BER Literature?}

After analyzing the qualifying articles, we found that $38 \%$ of them did not mention any specific active-learning strategy. 
A) Active Learning Definition Categories by Frequency

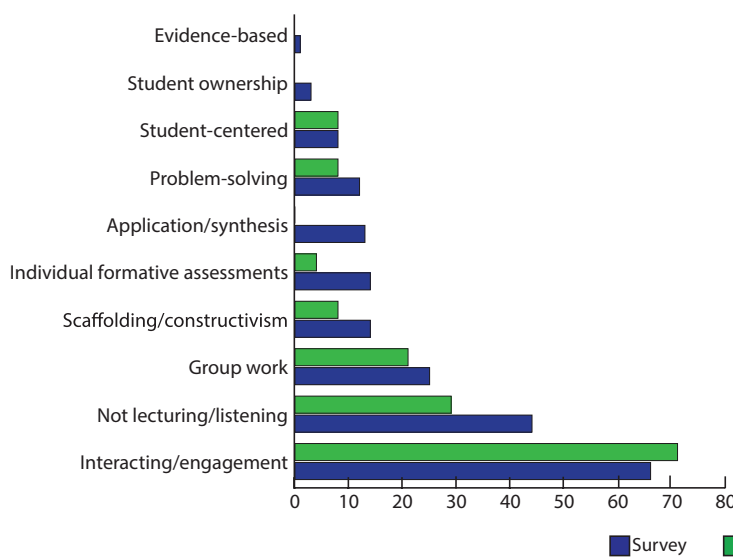

B) Active Learning Strategy Categories by Frequency

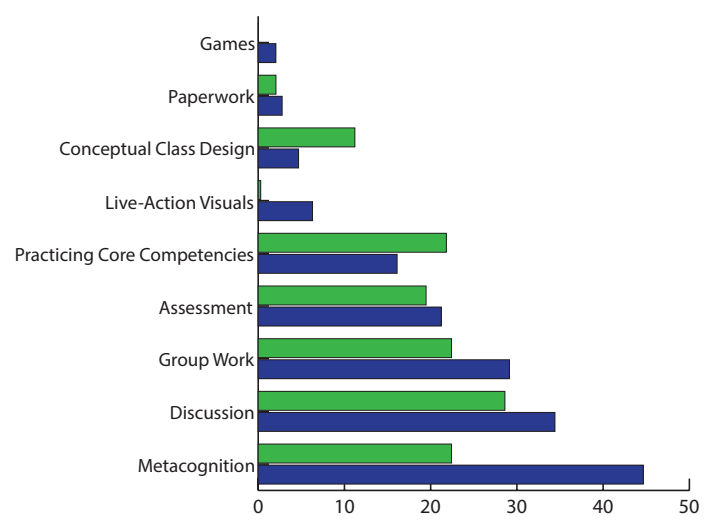

FIGURE 2. Frequency of how the BER literature and community define active learning and describe strategies. (A) The categorized definitions of active learning from the literature (LSE, Journal of Microbiology \& Biology Education, and CourseSource) and a survey disseminated to SABER members. Each bar shows the percentage of articles or total survey respondents who included the corresponding term in their definition of active learning or list of active-learning strategies. (B) The categorized active-learning strategies from the same BER literature and community sources. The graph is organized by increasing percentage of total survey responses in each category. The percent values represented in each figure do not add up to $100 \%$, because each literature source and survey response could have more than one strategy or definition represented.

From the papers that mentioned active-learning strategies, a total of 339 strategies were extracted, with 133 of them being unique responses. Once these strategies were categorized, the data revealed the most frequently represented strategy categories from the literature were discussion (29\%), group work (22\%), and metacognition (22\%; Figure 2B).

\section{How Are Active-Learning Strategies Described by the BER Community?}

We asked survey participants to respond to the prompt "List the active-learning strategies that you use in biology classrooms." We collated a list of 681 strategies from the responses, of which 201 were unique. After categorizing these strategies, we found the most frequently represented strategy categories from the surveys were discussion (34\%), group work (29\%), and metacognition (45\%; Figure 2B).

\section{DISCUSSION}

Our aim was to bring clarity and transparency to the term "active learning" as it is used within the BER community. We addressed this by identifying the definitions and strategies attributed to the term by analyzing the literature and surveying a BER society. From these compiled findings, we constructed an active-learning definition (see Box 1) as well as a reference guide for $300+$ defined active-learning strategies (Supplemental Appendix B).

Below we propose future steps for the BER community with accompanying tools to aid in the process. First, we advocate for all BER concerning active learning to provide a cited definition. Second, we suggest authors define and describe the active-learning strategies used in the experimental research.

\section{Define the Term}

Active learning has rarely been defined in the literature. This outcome could be due to the lack of a unanimous definition for the BER community; the fact that active learning is a complex process encompassing both teaching methods and student learning (Eddy et al., 2015); the dichotomous nature of the term as both a theory and as a set of pedagogical strategies (Drew and Mackie, 2011); the perception that this term is self-descriptive; and/or the notion that it is unimportant, given the majority of the research articles focused on the effects of the implementation of a specific active-learning strategy. Whatever the reason, we advocate for the inclusion of definitions in BER articles in order to clarify the author's interpretation. This is because, based on our investigation into the contemporary literature, it is apparent that people interpret active learning in a variety of different ways (i.e., interacting/engagement, not lecturing/listening, group work, scaffolding/constructivism, individual formative assessments, application/synthesis, problem solving, student centered, and evidence based). Ultimately, providing a definition may aid in increased fidelity and reproducibility of experimental outcomes (Stains and Vickrey, 2017).

When considering outcomes such as those demonstrated by Freeman et al. (2014; i.e., active learning decreased failure rates by $55 \%$ and increased student examination performance by approximately half a standard deviation), increased fidelity and reproducibility of experimental outcomes is important, especially because the promotion of undergraduate biology knowledge in the United States is consequential to critical scientific advances. To help in these efforts, we provide a number of resources and suggestions. First, we provided all of the definitions of active learning collected from recent BER literature in addition to the references used to support them, when applicable (Table 2). We also constructed a working definition of active learning based on the summarized input from the 148 articles found in the BER literature and the 105 responses from the BER community. This definition can be used confidently by the BER community in their own research, given it is based on an average of BER literature and instructor responses. 
TABLE 2. Active-learning definitions pulled from the literature ${ }^{a}$

Citation Active-learning definition

Auerbach and Schussler "Active learning is a student-centered pedagogical approach that engages student thinking through the use of class

(2017)

Ballen et al. (2017)

Becker et al. (2017)

Bentley and Connaughton (2017)

Bouwma-Gearhart et al. (2018)

Cavanagh et al. (2018).

Connell, Donovan and Chambers (2016)

Cooper et al. (2017a)

Cooper and Brownell (2016)

Cooper et al. (2018)

Cooper et al. (2017b)

Dewsbury (2017)

Durham, Knight and Couch (2017)

Elliott et al. (2016)

Goff et al. (2017)

Green, McMahon and Brame (2016).

Hoefnagels and Taylor (2016)

Jeno et al. (2017)

Kudish et al. (2016)

Lee et al. (2018)

McCourt et al. (2017)

McLean and Suchman (2016)

Moss-Racusin et al. (2016)

Stoltzfus and Libarkin (2016) activities that require students to reflect upon and often explicitly discuss their ideas and their application." 1,2 "Characterized by in-class activities, pre-lecture preparation, and frequent low-risk assessment." 3,4,5,6,7

"Active-learning ... requires students to take responsibility for their own knowledge level." 8

"Active learning occurs whenever students participate in an activity that allows them to process or synthesize course content."

"Part of student engagement (i.e., active learning is anything that engages students)."

"Active learning involves a range of student-centered pedagogies that encourage engagement through activities such as peer collaboration, experimentation, writing, and problem solving." 9, 10

"Active-learning pedagogies are intended to move classrooms toward more student-centered learning, and they engage students in knowledge construction. This context is in contrast to traditional lecture, which focuses on dissemination of instructor knowledge and relies on passive student listening."

"In contrast to instructors predominantly transmitting information to students by lecturing during class, active-learning classrooms give students the opportunity to construct their own knowledge, often through group work with other students." 7, 8, 11, 12, 18

"In active-learning classes, students are asked and often required to actively engage with other students and the instructor... there is not a single, agreed-upon definition of active learning."

Students engage in constructing their own knowledge during class. $7,13,14,15$

"In contrast to traditional lecture, students in active-learning classrooms are expected to interact more frequently with one another as well as with the instructor." $12,16,17,18$

"Active learning is a broad concept."

"Students are explicitly asked to engage in thinking about course material during class."19, 20, 21

"Active-learning strategies require students to engage with concepts and then provide students with feedback on their learning process."

"The active engagement of students in the learning process." ${ }^{13,23}$

"The main aspects of active learning: learning by doing and metacognition."

"Active learning is difficult to define, but the overall goal is simple: to reduce the amount of time that students spend passively listening to lectures."

"Active learning requires students to actively interact with the learning material and has been shown to have a positive effect on retention, as well as reducing dropout and failure rates." 7, 24

"[Active learning] require[s] critical integrative and analytical thinking." 7, 25, 26

"Active learning ... focuses on moving students from passively receiving and replicating instruction to actively using, testing, and formulating what they are learning for themselves."

"Active learning...can be defined as pedagogies that require students to engage directly in and take responsibility for their own learning. In practice, active learning occurs when instructors stop lecturing and provide time for students to complete activities that build conceptual understanding."

"Active learning advocates contend that when students do something they learn it better than if they just hear and see it."27

"A collection of teaching methods that engage learners and provide practice in scientific thinking." , 28, 29, 30, 31, 32

"Active learning is based on constructivist theory—-the idea that students must create their own knowledge in order for learning to persist. One core feature of active learning in the classroom is a decrease in lecturing during which students passively listen and an increase in outcome-related activities in which students actively develop their own understanding." $1,33,34,35,36,37,38,39,40,41,42,43$

aCitations available in Supplemental Appendix D.

\section{Define the Strategies}

The research papers we examined commonly listed active-learning strategies. Many of the strategies were either 1) self-descriptive, that is, the meaning could be easily deciphered from the term (e.g., applying knowledge of other subjects, circulate to check for understanding, group brainstorming); 2) defined in the literature by Tanner (2013), Miller and Tanner (2015), or others; or 3) easily collapsed into one of the three most common categories (i.e., metacognition, group work, or

\section{BOX 1. Active Learning Defined}

Active learning is an interactive and engaging process for students that may be implemented through the employment of strategies that involve metacognition, discussion, group work, formative assessment, practicing core competencies, live-action visuals, conceptual class design, worksheets, and/ or games. 
discussion). However, many strategies lacked transparency, because authors did not describe how they were implemented. We found these cases problematic, because the strategies would be difficult to replicate. To improve clarity and transparency, we share with readers our comprehensive list of unique strategies, collected from both the literature and the surveys, with definitions from the literature, when available, as well as citations of articles in which they were used in practice (Supplemental Appendix B and C).

Additionally, we have created a living-document version of Supplemental Appendix B and C that can be viewed using the following link: www.ballenlab.org/active-learning-strategies-in -biolo. Contributions or constructive feedback from the community is welcome; you can make a submission by contacting the lead author or using the following Google form: https://forms .gle/Boh6NNm1rqzHACXi8. This feedback will be considered and used by the lead author to improve the living document going forward. Our hope is that biology education researchers and teachers use these tools to define active-learning strategies they have used or as guides to articles that previously implemented these strategies. It is important to note that the strategies used and the efficacy measured in those studies may vary based on fidelity of implementation.

Another way to increase the precision of descriptions is the use of observation protocols that can characterize classroom instruction behaviors. Some examples include the Teaching Dimensions Observation Protocol (Hora et al., 2013), the Classroom Observation Protocol for Undergraduate STEM (Smith et al., 2013), the Practical Observation Rubric to Assess Active Learning (Eddy et al., 2015), and the Measurement Instrument for Scientific Teaching (Durham et al., 2017). These protocols document the frequency of multiple instructional practices, include categories of active-learning strategies, and can be helpful both for research purposes and to provide feedback to instructors on their practices. Such information can provide valuable guidance to biology educators, especially when used in conjunction with data on student performance, attitudes, social psychological factors, and self-reflective practices.

\section{Limitations and Future Work}

One limitation of this work is that the active-learning definitions and strategies were solicited from the BER community only. While we hypothesize that these definitions and strategies may overlap with other DBER subjects (chemistry, geology, physics, etc.), we cannot generalize our results across disciplines, given results from Lund and Stains (2015) revealed differences in the factors influencing the adoption of evidence-based instructional practices among disciplinary chemistry, biology, and physics faculty. However, many of the strategies featured in the Active-Learning Strategy Guide may be useful across disciplines. Additionally, it is reasonable to expect we may have received different active-learning definitions and strategies from disciplinary biology instructors or teaching practitioners who do not have a BER background. While seeking that information is out of the scope of this research, the BER community would benefit from engaging with the larger community to see how their work is translated among practitioners.

Second, while it is important to understand how active learning is used in classroom environments-particularly those that result in improved student outcomes-we recognize this does not control for instructors' fidelity of implementation. Fidelity of implementation is how well an intervention or activity is implemented in comparison with the original program's intention (O'Donnell, 2008; Stains and Vickrey, 2017), and this can strongly impact the efficacy of the pedagogy. So, as we continue to test active-learning strategies, it is critical to describe how and why certain pedagogies are enacted in the classroom.

Third, we examined only three journals that commonly publish BER. This means the findings are not representative of all BER that has been published during that time period. However, the three journals we focused on are commonly used by the BER community. For example, LSE and the Journal of Microbiology \& Biology Education publish primarily research articles and have a long-standing history and a large readership; CourseSource is the only online journal that exclusively publishes evidence-based biology teaching materials for undergraduate classrooms and laboratories.

Future work will 1) identify to what extent-and howactive learning is characterized across the DBER literature; 2) characterize the definition of active learning in the context of undergraduate STEM by collecting survey data from DBER communities across STEM fields; 3) categorize the specific active-learning strategies employed across STEM disciplines through survey data; and 4) investigate to what extent, if at all, perceptions of active learning differ among DBER communities across STEM fields.

\section{CONCLUSIONS}

We support the use of active learning as a unifying term to generate awareness and collaboration among those interested in improving their teaching. The term gives DBER instructors an accessible on-ramp to engage with larger initiatives. However, because the term is rarely defined and can have many different meanings, those who use active learning should define what they mean and give examples of the strategies they are using. For example, authors could say: "We used an active-learning instructional approach focused on student engagement using group work and clicker questions with peer instruction," followed by the appropriate citations and additional detail about the application and frequency of strategies. These additional details will allow the community to address more nuanced questions, such as: Do specific active-learning instructional strategies promote student learning in multiple environments? Which strategies increase equitable outcomes for students from diverse backgrounds? How can we maximize the effectiveness of a particular active-learning strategy in a variety of contexts? These questions can be more effectively answered when the approach and context of the learning environment is precisely defined. This clarity has the potential to make DBER communities, and their research, stronger.

\section{ACKNOWLEDGMENTS}

We are grateful to the DBER group at Auburn University for valuable feedback and to Taylor McKibben, Sara Wood, Brian Peters, and Brittany Woodruff for helping with data collection and analysis. We would also like to thank Doug Lombardi and Tim Shipley for their support and encouragement and two anonymous reviewers for critical insights that greatly improved the article. 


\section{REFERENCES}

Ackermann, E. (2001). Piaget's constructivism, Papert's constructionism: What's the difference. Future of Learning Group Publication, 5(3), 438.

Alexander, B., Ashford-Rowe, K., Barajas-Murph, N., Dobbin, G., Knott, J., McCormack, M., ... \& Weber, N. (2019). In EDUCAUSE Horizon Report: 2019 Higher Education Edition (pp. 3-41). Retrieved May 10, 2020, from https://library .educause.edu/-/media/files/library/2019/4/2019horizonreport .pdf?la=en\&hash=C8E8D444AF372E705FA1BF9D4FF0DD4CC6F0FDD1

American Association for the Advancement of Science. (2009). Vision and change: A call to action. Washington, DC. Retrieved January 29, 2020, from https://live-visionandchange.pantheonsite.io/wp-content/uploads/ 2011/03/VC-Brochure-V6-3.pdf

Aragón, O. R., Eddy, S. L., \& Graham, M. J. (2018). Faculty beliefs about intelligence are related to the adoption of active-learning practices. CBELife Sciences Education, 17/3, ar47

Auerbach, A. J., \& Schussler, E. (2017). A Vision and Change reform of introductory biology shifts faculty perceptions and use of active learning. CBE-Life Sciences Education, 16(4), ar57.

Ballen, C. J., Wieman, C., Salehi, S., Searle, J. B., \& Zamudio, K. R. (2017). Enhancing diversity in undergraduate science: Self-efficacy drives performance gains with active learning. CBE-Life Sciences Education, 16(4), ar56.

Bauer, A. C., Coffield, V. M., Crater, D., Lyda, T., Segarra, V. A., Suh, K., ... \& Vigueira, P. A. (2020). Fostering Equitable Outcomes in Introductory Biology Courses through Use of a Dual Domain Pedagogy. CBE-Life Sciences Education, 19(1), ar4.

Becker, E. A., Easlon, E. J., Potter, S. C., Guzman-Alvarez, A., Spear, J. M., Facciotti, M. T., ... \& Pagliarulo, C. (2017). The effects of practice-based training on graduate teaching assistants' classroom practices. CBE-Life Sciences Education, 16(4), ar58

Beichner, R. J., Saul, J. M., Abbott, D. S., Morse, J. J., Deardorff, D., Allain, R. J., ... \& Risely, J. S. (2007). The student-centered activities for large enrollment undergraduate programs (SCALE-UP) project. Research-Based Reform of University Physics, 1(1), 2-39.

Bentley, M., \& Connaughton, V. P. (2017). A simple way for students to visualize cellular respiration: Adapting the board game Mousetrap ${ }^{\top M}$ to model complexity. CourseSource. https://doi.org/10.24918/cs.2017.8

Bouwma-Gearhart, J. L., Ivanovitch, J. D., Aster, E. M., \& Bouwma, A. M. (2018). Exploring postsecondary biology educators' planning for teaching to advance meaningful education improvement initiatives. CBE-Life Sciences Education, 17(3), ar37.

Brown, J. S., Collins, A., \& Duguid, P. (1989). Situated cognition and the culture of learning. Educational Researcher, 18(1), 32-42.

Cavanagh, A. J., Chen, X., Bathgate, M., Frederick, J., Hanauer, D. I., \& Graham, M. J. (2018). Trust, growth mindset, and student commitment to active learning in a college science course. CBE-Life Sciences Education, 17(1), ar10.

Connell, G. L., Donovan, D. A., \& Chambers, T. G. (2016). Increasing the use of student-centered pedagogies from moderate to high improves student learning and attitudes about biology. CBE-Life Sciences Education, 15(1), ar3.

Cook, B. G., Smith, G. J., \& Tankersley, M. (2012). Evidence-based practices in education. In Harris, K. R., Graham, S., Urdan, T., McCormick, C. B., Sinatra, G. M., \& Sweller, J. (Eds.), APA handbooks in psychology®. APA educational psychology handbook, Vol. 1. Theories, constructs, and critical issues (pp. 495-527). American Psychological Association.

Cooper, K. M., Ashley, M., \& Brownell, S. E. (2017a). A bridge to active learning: A summer bridge program helps students maximize their active-learning experiences and the active-learning experiences of others. CBE-Life Sciences Education, 16(1), ar17.

Cooper, K. M., \& Brownell, S. E. (2016). Coming out in class: Challenges and benefits of active learning in a biology classroom for LGBTQIA students. CBE-Life Sciences Education, 15(3), ar37.

Cooper, K. M., Ding, L., Stephens, M. D., Chi, M. T., \& Brownell, S. E. (2018). A course-embedded comparison of instructor-generated videos of either an instructor alone or an instructor and a student. CBE-Life Sciences Education, 17(2), ar31.

Cooper, K. M., Haney, B., Krieg, A., \& Brownell, S. E. (2017b). What's in a name? The importance of students perceiving that an instructor knows their names in a high-enrollment biology classroom. CBE-Life Sciences Education, 16(1), ar8.

Dewey, J. (1916). Democracy and education. New York: McMillan.

Dewsbury, B. M. (2017). Context determines strategies for "activating" the inclusive classroom. Journal of Microbiology \& Biology Education, 18(3). doi: 10.1128/jmbe.v18i3.1347

Drew, V., \& Mackie, L. (2011). Extending the constructs of active learning: Implications for teachers' pedagogy and practice. Curriculum Journal, 22(4), 451-467.

Durham, M. F., Knight, J. K., \& Couch, B. A. (2017). Measurement Instrument for Scientific Teaching (MIST): A tool to measure the frequencies of research-based teaching practices in undergraduate science courses. CBE-Life Sciences Education, 16(4), ar67.

Eddy, S. L., Converse, M., \& Wenderoth, M. P. (2015). PORTAAL: A classroom observation tool assessing evidence-based teaching practices for active learning in large science, technology, engineering, and mathematics classes. CBE-Life Sciences Education, 14(2), ar23. doi: 10.1187/cbe.14-06-0095

Eddy, S. L., \& Hogan, K. A. (2014). Getting under the hood: How and for whom does increasing course structure work? CBE-Life Sciences Education, 13(3), 453-468.

Elliott, E. R., Reason, R. D., Coffman, C. R., Gangloff, E. J., Raker, J. R., Powell-Coffman, J. A., \& Ogilvie, C. A. (2016). Improved student learning through a faculty learning community: How faculty collaboration transformed a large-enrollment course from lecture to student centered. CBE-Life Sciences Education, 15(2), ar22.

Freeman, S., Eddy, S. L., McDonough, M., Smith, M. K., Okoroafor, N., Jordt, H., \& Wenderoth, M. P. (2014). Active learning increases student performance in science, engineering, and mathematics. Proceedings of the National Academy of Sciences USA, 111(23), 8410-8415. doi: 10.1073/ pnas.1319030111

Glaser, B. G., Strauss, A. L., \& Strutzel, E. (1968). The discovery of grounded theory; strategies for qualitative research. Nursing Research, 17(4), 364.

Goff, E. E., Reindl, K. M., Johnson, C., McClean, P., Offerdahl, E. G., Schroeder, N. L., \& White, A. R. (2017). Efficacy of a meiosis learning module developed for the virtual cell animation collection. CBE-Life Sciences Education, 16(1), ar9.

Green, N. H., McMahon, D. G., \& Brame, C. (2016). Using online active-learning techniques to convey time compensated sun compass orientation in the eastern North American monarch. Journal of Microbiology \& Biology Education, 17(3), 430.

Haak, D. C., HilleRisLambers, J., Pitre, E., \& Freeman, S. (2011). Increased structure and active learning reduce the achievement gap in introductory biology. Science, 332(6034), 1213-1216. doi: 10.1126/science.1204820

Hoefnagels, M., \& Taylor, M. S. (2016). "Boost your evolution IQ": An evolution misconceptions game. CourseSource. https://doi.org/10.24918/cs.2016.12

Hora, M. T., Oleson, A., \& Ferrare, J. J. (2013). Teaching Dimensions Observation Protocol (TDOP) user's manual. Madison: Wisconsin Center for Education Research.

Jeno, L. M., Raaheim, A., Kristensen, S. M., Kristensen, K. D., Hole, T. N., Haugland, M. J., \& Mæland, S. (2017). The relative effect of team-based learning on motivation and learning: A self-determination theory perspective. CBE-Life Sciences Education, 16(4), ar59.

Kreber, C., \& Cranton, P. A. (2000). Exploring the scholarship of teaching Journal of Higher Education, 71(4), 476-495.

Kudish, P., Shores, R., McClung, A., Smulyan, L., Vallen, E. A., \& Siwicki, K. K. (2016). Active learning outside the classroom: Implementation and outcomes of peer-led team-learning workshops in introductory biology. CBE-Life Sciences Education, 15(3), ar31.

Kuhn, T. (1970). The structure of scientific revolutions. Chicago: University of Chicago Press.

Lee, C. J., Toven-Lindsey, B., Shapiro, C., Soh, M., Mazrouee, S., Levis-Fitzgerald, M., \& Sanders, E. R. (2018). Error-discovery learning boosts student engagement and performance, while reducing student attrition in a bioinformatics course. CBE-Life Sciences Education, 17(3), ar40.

Lund, T. J., \& Stains, M. (2015). The importance of context: An exploration of factors influencing the adoption of student-centered teaching among chemistry, biology, and physics faculty. International Journal of STEM Education, 2, 13 
McCourt, J. S., Andrews, T. C., Knight, J. K., Merrill, J. E., Nehm, R. H., Pelletreau, K. N., ... \& Lemons, P. P. (2017). What motivates biology instructors to engage and persist in teaching professional development? CBELife Sciences Education, 16(3), ar54.

McLean, J. L., \& Suchman, E. L. (2016). Using magnets and classroom flipping to promote student engagement and learning about protein translation in a large microbiology class. Journal of Microbiology \& Biology Education, 17(2), 288.

Miller, S., \& Tanner, K. D. (2015). A portal into biology education: An annotated list of commonly encountered terms. CBE-Life Sciences Education, 14(2), fe2.

Montessori, M. (1946). Education for a new world (Vol. 1). Adyar, Madras, India: Kalakshetra.

Moss-Racusin, C. A., van der Toorn, J., Dovidio, J. F., Brescoll, V. L., Graham, M. J., \& Handelsman, J. (2016). A "scientific diversity" intervention to reduce gender bias in a sample of life scientists. CBE-Life Sciences Education, 15(3), ar29.

O'Donnell, C. L. (2008). Defining, conceptualizing, and measuring fidelity of implementation and its relationship to outcomes in $\mathrm{K}-12$ curriculum intervention research. Review of Educational Research, 78(1), 33-84.

Papert, S. (1980). Mindstorms: Computers, children, and powerful ideas (pp. 607). New York: Basic Books.

Pesavento, T., Klein, J., Macasaet, D., Shorter, C., \& Wagstaff, S. (2015). History \& context for active learning. Retrieved February 15, 2020, from https:// wisc.pb.unizin.org/teachingwithtech/chapter/history-context-for -active-learning/\#: :text=Theterm"active learning"

Pfund, C., Miller, S., Brenner, K., Bruns, P., Chang, A., Ebert-May, D., Fagen, A P. et al. (2009). Summer institute to improve university science teaching. Science, 324(5926), 470-471.

Piaget, J. (1932). The moral judgment of the child. San Diego, CA: Harcourt, Brace.

President's Council of Advisors on Science and Technology. (2012). Engage to excel: Producing one million additional college graduates with degrees in science, technology, engineering, and mathematics. Washington, DC: U.S. Government Office of Science and Technology.
Saldaña, J. (2015). The coding manual for qualitative researchers. Los Angeles, $\mathrm{CA}$ and London: Sage.

Smith, M. K., Jones, F. H. M., Gilbert, S. L., \& Wieman, C. E. (2013). The Classroom Observation Protocol for Undergraduate STEM (COPUS): A new instrument to characterize university STEM classroom practices. CBELife Sciences Education, 12(4), 618-627.

Stains, M., \& Vickrey, T. (2017). Fidelity of implementation: An overlooked yet critical construct to establish effectiveness of evidence-based instructional practices. CBE-Life Sciences Education, 16(1), rm1.

Stoltzfus, J. R., \& Libarkin, J. (2016). Does the room matter? Active learning in traditional and enhanced lecture spaces. CBE-Life Sciences Education, 15(4), $\operatorname{ar} 68$

Strauss, A., \& Corbin, J. (1990). Basics of qualitative research: Grounded theory procedures and techniques. Newbury Park, CA: Sage.

Strauss, A. L. (1987). Qualitative analysis for social scientists. Cambridge: Cambridge University Press.

Tanner, K. D. (2013). Structure matters: Twenty-one teaching strategies to promote student engagement and cultivate classroom equity. CBE-Life Sciences Education, 12(3), 322-331.

Theobald, E. J., Hill, M. J., Tran, E., Agrawal, S., Arroyo, E. N., Behling, S., ... \& Grummer, J. A. (2020). Active learning narrows achievement gaps for underrepresented students in undergraduate science, technology, engineering, and math. Proceedings of the National Academy of Sciences USA, 117(12), 6476-6483.

Turkle, S., \& Papert, S. (1990). Epistemological pluralism: Styles and voices within the computer culture. Signs: Journal of Women in Culture and Society, 16(1), 128-157.

Vygotsky, L. S. (1987). The development of scientific concepts in childhood. In The collected works of LS Vygotsky (Vol. 1, pp. 167-241) New York City, New York: Springer US.

Wilton, M., Gonzalez-Niño, E., McPartlan, P., Terner, Z., Christoffersen, R. E., \& Rothman, J. H. (2019). Improving academic performance, belonging, and retention through increasing structure of an introductory biology course. CBE-Life Sciences Education, 18(4), ar53. 